\title{
EUROSON 2020 Bergen, Norway - cancelled
}

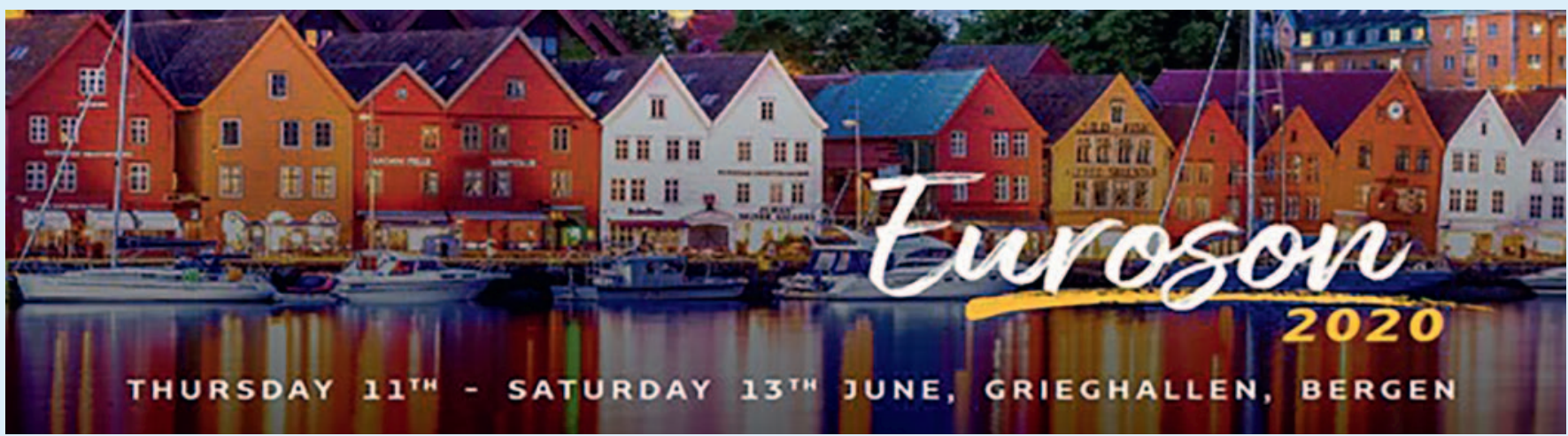

\author{
EUROPEAN FEDERATION OF SOCIETIES FOR ULTRASOUND IN MEDICINE AND BIOLOGY \\ "Educating all for competence to practice ultrasound safely" \\ Young investigator's Award \\ EUROSON 2020 Bergen, Norway \\ 12 June $\mathbf{1 0 . 0 0 - 1 1 . 4 5}$ on GoToWebinar \\ 7 minutes each for presentation plus 3 minutes discussion
}

\begin{tabular}{|c|c|c|c|}
\hline Introduction & $10.00-10.05$ & Roald F. Havre & Welcome \& Presentation of the program, speakers, chairmen and committee \\
\hline Austria & $10.05-10.15$ & Patrick Greimel & $\begin{array}{l}\text { Abdominal decompression is a major contributor to amniodrainage induced } \\
\text { circulatory dysfunction following intrauterine interventions for twin-to-twin } \\
\text { transfusion syndrome }\end{array}$ \\
\hline Denmark & $10.15-10.25$ & Tobias Todson & $\begin{array}{l}\text { A randomized multicenter clinical trial comparing transoral ultrasound versus } \\
\text { standard of care in the management of patient suspected with peritonsillar } \\
\text { abscess }\end{array}$ \\
\hline Romania & $10.25-10.35$ & Tudor Mocan & $\begin{array}{l}\text { In vivo performance of PEG-coated gold nanoparticles mediated ultrasound } \\
\text { guided radiofrequency ablation: a pilot study in swine }\end{array}$ \\
\hline Italy & $10.35-10.45$ & Damiano D’Ardes & $\begin{array}{l}\text { Effects of diet and nutraceuticals on patients with metabolic syndrome and non- } \\
\text { alcoholic hepatic steatosis evaluated with an ultrasonographic and elastographic } \\
\text { approach }\end{array}$ \\
\hline Netherlands & $10.45-10.55$ & Thomas van den Heuvel & $\begin{array}{l}\text { Introducing prenatal ultrasound screening in research-limited settings using } \\
\text { artificial intelligence }\end{array}$ \\
\hline Greece & $10.55-11.05$ & Stavros Grigoriadis & Effectiveness and Safety of Fusion Imaging \\
\hline UK & $11.05-11.15$ & Simone Ambrogio & $\begin{array}{l}\text { Towards a standard test phantom for Magnetic Resonance guided High Intensity } \\
\text { Focused Ultrasound (MRgHIFU) }\end{array}$ \\
\hline Norway & $11.15-11.25$ & Anders Hagen Jarmund & $\begin{array}{l}\text { Characterization of Instant Hemodynamic Responses to Tilt in Healthy Term } \\
\text { Neonates using NeoDoppler }\end{array}$ \\
\hline Short Break & $11.25-11.30$ & & $\begin{array}{l}\text { Judges meeting assessing in the usual way in terms of clinical and scientific } \\
\text { relevance, methodology, results, interpretation and presentation. }\end{array}$ \\
\hline Prize award & $11.30-11.40$ & $\begin{array}{l}\text { Maja Radzina and } \\
\text { Adrian Lim }\end{array}$ & $\begin{array}{l}\text { Award of the } 3000 \text { euro prize for the best clinical and/or best technical } \\
\text { presentation }\end{array}$ \\
\hline
\end{tabular}


The Young Investigator session is usually one of the highlights of the EUROSON conference. This year, however we had to cancel the conference, but we still want to keep some sessions in the form of webinars. We would like to welcome everyone interested to join our Young Investigator session on GoToWebinar on Friday June 12. 10-12 (CET). An invitation will be distributed through the EFSUMB homepage, and through EFSUMB members e-mails. A recording of the sessions will be available on the EFSUMB homepage in the member section after the webinar. The webinar will be free to join for all interested up to 600 , but a pre-webinar registration is required.

During the live sessions, presenters will have $7 \mathrm{~min}$ for presentations and $3 \mathrm{~min}$ for questions, so we hope there will be an active audience. The Young Investigator session bring new and brave projects to the stage, and we get to meet some new presenters and ask them directly about their interesting projects. This year we have a particularly interesting list of topics, which we really look forward to hearing more about.

The program is still not confirmed by all participants, so some changes may occur. The recording will be available on the EFSUMB website for later viewing.

\section{Welcome to an EFSUMB webinar on gastrointestinal ultrasound (GIUS) Thursday June 11., 14.00-16.00 CEST}

The last couple of months the world has moved from face-to-face encounters to online meetings. Although the physical EUROSON 2020 has been cancelled, we would like to offer you a taste of what we had to offer in Bergen with a webinar on gastrointestinal ultrasound.

Gastrointestinal ultrasound (GIUS) has received increasing interest in recent years as the need of non-invasive tools for repeated investigations has escalated. EFSUMB has been crucial in the development the first guidelines ever and recommendations in this field. The programme is focused on presenting these guidelines as well as the practical use of GIUS in IBD and in acute intestinal disorders.

Programme:

14.00-14.05: Introduction:

Kim Nylund (Chair)

14.05-14.30: Overview of the GIUS guidelines and position statements from EFSUMB: Odd Helge Gilja

14.30-14.55 GIUS and fibrosis in Crohn's disease: Giovanni Maconi (to be confirmed) 14.55-15.20 GIUS and disease activity in ulcerative colitis: Christian Maaser

15.20-15.45 Ultrasound in acute intestinal disorders: Matthias Wüstner (to be confirmed)

15.45-16.00 Q and A with lecturers and conclusion

As this is still work in progress, we are obliged to inform you that this is a preliminary programme and may be subject to change. 